\title{
Interrelationship between vitamin A, iodine and iron status in schoolchildren in Shoa Region, Central Ethiopia
}

\author{
BY ZEWDIE WOLDE-GEBRIEL ${ }^{1}$, CLIVE E. WEST ${ }^{2 *}$, HAILE GEBR ${ }^{1}$, \\ AMHA-SELASSIE TADESSE ${ }^{1}$, TEZERA FISSEHA ${ }^{1}$, PETROS GABRE ${ }^{1}$, \\ CHERNET ABOYE ${ }^{1}$, GONFA AYANA ${ }^{3}$ AND JOSEPH G. A. J. HAUTVAST ${ }^{2}$ \\ ${ }^{1}$ Ethiopian Nutrition Institute, PO Box 5654, Addis Ababa, Ethiopia \\ ${ }^{2}$ Department of Human Nutrition, Wageningen Agricultural University, PO Box 8129 , \\ $6700 \mathrm{EV}$ Wageningen, The Netherlands \\ ${ }^{3}$ National Health Research Institute, PO Box 1242, Addis Ababa, Ethiopia
}

(Received 5 February 1992 - Accepted 8 October 1992)

\begin{abstract}
A total of 14740 schoolchildren in seven provinces of Shoa Administrative Region in Central Ethiopia were surveyed for the prevalence of goitre, xerophthalmia and anaemia. Haemoglobin and packed cell volume were assessed in 966 children in one province while an in-depth study was conducted on 344 children in the same province and two others. Goitre, xerophthalmia (Bitot's spots) and clinical anaemia were observed in $34 \cdot 2,0.91$ and $18.6 \%$ respectively of the children. Most biochemical variables were within the normal range while those of haemoglobin $(\mathrm{Hb})$, mean corpuscular $\mathrm{Hb}$ concentration (MCHC) and urinary I excretion were lower, and mean corpuscular volume, mean corpuscular $\mathrm{Hb}$ (MCH), and immunoglobulins $\mathrm{G}$ and $\mathrm{M}$ were higher. $\mathrm{Hb}$ was strongly correlated with retinol, ferritin, $\mathrm{MCHC}, \mathrm{MCH}$, packed cell volume and erythrocyte count while retinol formed a triad with transthyretin (TTR) and retinol-binding protein (RBP) which were all correlated with one another. Total and free thyroxin and total and free triiodothyronine were positively correlated as were the concentrations of the total and free hormones. Thyrotropin (TSH) was negatively correlated with total and free thyroxin and positively correlated with free triiodothyronine. Thyroxin and triiodothyronine in both free and combined forms were all correlated with thyroxin-binding globulin which in turn was negatively correlated with the triad retinol, RBP and TTR. The triad was also negatively correlated with C-reactive protein. Urinary 1 excretion was positively associated with total thyroxin and negatively associated with TSH. The anaemia found was not nutritional in origin but due to the effect of infestation with intestinal parasites and malaria.
\end{abstract}

Vitamin A: Iodine: Iron: Childhood

The three most important nutritional problems in developing countries are those due to deficiency of vitamin A, I and Fe. Every year as a result of vitamin A deficiency 250000 children go blind and another 250000 have their eye-sight impaired, and at least 100000 of those children die within a few weeks (Grant, 1991). Possibly even more children are affected because there is strong evidence that vitamin A deficiency increases morbidity from respiratory and gastrointestinal diseases and overall mortality (Anonymous, 1990). An estimated 800 million people in the world are at risk from I deficiency, with 190 million suffering from goitre, 3 million from overt cretinism and millions more from some degree of intellectual deficit (Grant, 1991). Anaemia is prevalent in many parts of the world, particularly in developing countries, with infants, young children and pregnant women, the latter two groups being most vulnerable because of their increased physiological requirements not only for $\mathrm{Fe}$ but also for folic acid (DeMaeyer \& Adiels-Tegman, 1985).

* For reprints. 
In areas where intestinal parasitic infestations and malaria prevail the problem is exacerbated resulting in decreased work performance, higher morbidity and mortality during pregnancy, increased risk of infection, subnormal mental performance and behavioural changes (International Nutritional Anemia Consultative Group, 1977).

As in most developing countries, Ethiopia harbours all three nutritional problems (Interdepartmental Committee of Nutrition for National Defense, 1959; Hofvander, 1968; Wolde-Gebriel et al. 1991, 1993a). In our earlier papers care was taken to obtain representative samples of the population in the country. However, in the study reported in the present paper the purpose is to examine the interrelationships between the three nutritional conditions. Understanding such interrelationships enables the generation of hypotheses which can be tested in further studies such as intervention studies in humans and by using appropriate animal models. The areas in which the study was carried out were those chosen for a series of in-depth studies.

\section{MATERIALS AND METHODS}

Study sites and subjects

Schools, chosen at random, located along the main roads between Addis Ababa and the district and provincial towns of Shoa Administrative Region were surveyed. The baseline survey comprised two phases in which a total of 14740 schoolchildren ( 8779 males and 5961 females) from forty-four schools in seven provinces were clinically assessed in the first phase, while a more comprehensive study involving 344 boys with further measurement of biochemical and anthropometric variables was carried out in the second phase. In one of the provinces (Chebona-Gurage) haemoglobin ( $\mathrm{Hb}$ ) and packed cell volume measurements were carried out on the 966 schoolboys of the total 3725 boys seen during the first phase of the survey who were found to have pale tongues and buccal membranes, indicating anaemia. Informed consent in writing was obtained from Party, Health and Education Offices at Regional and Provincial level as well as from the school directors, while verbal consent was obtained from parents.

\section{Physical examination}

The physical examination comprised the following: examination of the eyes for signs of xerophthalmia which were classified as recommended by the World Health Organization (1982); palpation of the thyroid gland for the presence of goitre which was graded according to the method recommended by Delange et al. (1986); and assessment of anaemia on the basis of paleness of buccal membranes and tongue.

\section{Biochemical tests and analytical methods}

All analyses were carried out in duplicate. After transfer to the field laboratory, $\mathrm{Hb}$ was determined according to the cyanmethaemoglobin method of van Kampen \& Zijlstra (1961) and packed cell volume (PCV) was determined using the microhaematocrit centrifuge. In the second phase, erythrocytes (RBC) were counted by two senior technicians with many years of experience from Atat Hospital. Mean corpuscular volume (MCV), mean corpuscular $\mathrm{Hb}(\mathrm{MCH})$ and mean corpuscular $\mathrm{Hb}$ concentration (MCHC) were estimated from haemoglobin, PCV, and RBC values.

Also in the second phase, an additional $15 \mathrm{ml}$ blood was collected using the Vacutainer system (Venoject; Terumo, Belgium) without anticoagulant. Serum was separated within a few hours after collection and stored in deep-freezes of the local health institutions. They were then transported in cold boxes with cooling elements to the laboratories of the Ethiopian Nutrition Institute (ENI) where they arrived frozen and were stored at $-20^{\circ}$. All 
analyses were done in ENI except retinol, retinol-binding protein (RBP), transthyretin (TTR), immunoglobulins and C-reactive protein (CRP) which were done in The Netherlands. The specimens for the analyses in The Netherlands were sent by air in cold boxes with dry ice and then stored at $-20^{\circ}$ until analysed. All analyses on serum which were done in Ethiopia were carried out within 6 months of collection, while those done in The Netherlands were done within 2 years. Serum retinol was estimated by HPLC as described earlier (Wolde-Gebriel et al. 1993b) while RBP, TTR, transferrin, immunoglobulin A, G and M (IgA, IgG and IgM) and CRP were analysed by immunonephelometry using reagents and equipment supplied by Behringwerke $A G$, Germany, as described by Fink et al. (1989). Albumin was measured using the bromocresol green method of Doumas et al. (1971). Free and total triiodothyronine (FT3 and TT3), free and total thyroxin (FT4 and TT4), thyrotropin (TSH) and ferritin were measured by radioimmunoassay using kits supplied by Amersham International UK, and thyroxin (T4)-binding globulin (TBG) using the enzyme-linked immunosorbent assay (ELISA) method with kits supplied by Boehringer Mannheim, Germany. The TT4/TBG quotient, defined as ten times TT4 divided by TBG both expressed in nmol/1, was used to classify subjects as defined by Boehringer Mannheim as follows: hypothyroid $<3 \cdot 4$, borderline $3 \cdot 4-3 \cdot 9$, euthyroid $3 \cdot 9-6 \cdot 5$, borderline $6 \cdot 5-7 \cdot 7$, hyperthyroid $>7 \cdot 7$. Total Fe-binding capacity (TIBC) and serum Fe were measured as described by Schade et al. (1954).

Casual urine samples were collected and urinary I excretion was determined using the Sandell-Kolthoff reaction (Sandell \& Kolthoff, 1937). Specimens of food and drinking water were collected from some of these areas for the analysis of their I content as described previously while in some specimens of drinking water microbiological tests were also carried out.

\section{Statistics}

The significance of differences was compared using Chi-square and Mann-Whitney for pair testing and Kruskal-Wallis for multiple-variable testing as the data were not normally distributed. For examining correlations, data were checked for normal distribution and those with skewness values outside the range of -1 to +1 were regarded as skewed and the data were transformed to natural logarithms before correlation analysis.

\section{RESULTS \\ Clinical}

Goitre. The mean total prevalence for males and females of gross goitre in all schools was $32.7 \%$ (Table 1). In the seven provinces the prevalence ranged from $16.4 \%$ in Selale to $49.1 \%$ in Merhabete. The prevalence in females $(42.2 \%)$ was significantly higher $(P<0.001)$ than that in males $(26.2 \%)$ and the higher prevalence in females was found when all schools were taken individually or aggregated by province.

Xerophthalmia. As shown in Table 1, the average of mean prevalence values for males and females of Bitot's spots was $0.91 \%$. In the group as a whole, $1.4 \%$ of the children had corneal scars which were attributed to measles in $41.1 \%$, 'mitch' (an Amharic word used to describe a vague and ill-defined febrile illness) in $34.7 \%$, trauma in $13.9 \%$, non-specific eye illness in $6.9 \%$, chickenpox in $1.5 \%$ and was unknown in $1.9 \%$ of the children. More males $(71 \cdot 3 \%)$ had corneal scars than females $(28.7 \%)$.

Anaemia. Clinical anaemia was observed in $18.6 \%$ of the children examined (Table 1) and the prevalence was higher in boys $(20.9 \%)$ than in girls $(15.1 \%)$. This difference was observed in the age-groups 6-10 years and 11-14 years but not in those aged 15-18 years (Table 2). 
Table 1. Prevalence of goitre, xerophthalmia and anaemia among schoolchildren in seven provinces of Shoa Region, Ethiopia.

\begin{tabular}{|c|c|c|c|c|c|c|c|}
\hline \multirow[b]{3}{*}{ Sex } & \multirow{3}{*}{$\begin{array}{l}\text { No. of } \\
\text { schoolchildren } \\
\text { examined }\end{array}$} & \multicolumn{6}{|c|}{ Prevalence $(\%)$} \\
\hline & & \multicolumn{2}{|c|}{ Goitre } & \multicolumn{2}{|c|}{$\begin{array}{l}\text { Xerophthalmia } \\
\text { (Bitot's spots) }\end{array}$} & \multicolumn{2}{|c|}{ Anaemia } \\
\hline & & $n$ & $\%$ & $n$ & $\%$ & $n$ & $\%$ \\
\hline M & 8779 & 2297 & $26 \cdot 2$ & 98 & $1 \cdot 1^{* * *}$ & 1838 & $20.9 * * *$ \\
\hline $\mathrm{F}$ & 5961 & 2518 & $42 \cdot 2^{* * *}$ & 36 & $0 \cdot 6$ & 902 & $15 \cdot 1$ \\
\hline $\mathrm{M}+\mathrm{F}^{*}$ & 14740 & 4815 & $32 \cdot 7$ & 134 & 0.9 & 2740 & 18.6 \\
\hline
\end{tabular}

* The prevalence for the sexes combined, expressed as a percentage, was not corrected for the unequal number of males and females in the sample studied.

Prevalence values were significantly higher than those for the opposite sex: ${ }^{* * *} P<0 \cdot 001$.

Table 2. Prevalence of goitre, xerophthalmia and anaemia by sex in schoolchildren in seven provinces of Shoa Region, Ethiopia

\begin{tabular}{|c|c|c|c|c|c|c|c|c|c|c|c|c|}
\hline \multirow[b]{2}{*}{ Sex } & & \multicolumn{5}{|c|}{ Goitre grade } & \multicolumn{3}{|c|}{ Xerophthalmia } & \multicolumn{2}{|c|}{ Anaemia } & \multirow[b]{2}{*}{ Total } \\
\hline & & 0 & IA & IB & II & III & Absent & $\begin{array}{l}\text { Bitot's } \\
\text { spots }\end{array}$ & $\begin{array}{l}\text { Corneal } \\
\text { scar }\end{array}$ & Absent & Present & \\
\hline M & $n$ & 6482 & 1588 & 631 & 77 & 1 & 8537 & 98 & 144 & 6941 & 1838 & 8779 \\
\hline & $\%$ & $73 \cdot 8$ & $18 \cdot 1$ & 7.2 & 0.9 & $0 \cdot 0$ & $97 \cdot 2$ & $1 \cdot 1$ & 1.6 & $79 \cdot 1$ & $20 \cdot 9$ & $100 \cdot 0$ \\
\hline $\mathrm{F}$ & $\begin{array}{l}n \\
\%\end{array}$ & $\begin{array}{c}3443 \\
57 \cdot 8\end{array}$ & $\begin{array}{l}1330 \\
22 \cdot 3\end{array}$ & $\begin{array}{l}991 \\
16.6\end{array}$ & $\begin{array}{l}190 \\
3.2\end{array}$ & $\begin{array}{l}7 \\
0 \cdot 1\end{array}$ & $\begin{array}{c}5867 \\
98 \cdot 4\end{array}$ & $\begin{array}{l}36 \\
0 \cdot 6\end{array}$ & $\begin{array}{l}58 \\
1.0\end{array}$ & $\begin{array}{c}5059 \\
84 \cdot 9\end{array}$ & $\begin{array}{l}902 \\
15.1\end{array}$ & $\begin{array}{c}5961 \\
100 \cdot 0\end{array}$ \\
\hline
\end{tabular}

\section{Clinical chemistry}

In children examined in Chebona-Gurage in the first phase of the study the median $\mathrm{Hb}$ concentration (mmol/l) and PCV values (with 25 th and 75 th percentiles respectively) were $7.63(7 \cdot 14$ and $8 \cdot 19 ; n 966)$ and $0.40(0.38$ and $0.41 ; n 966)$ respectively. The median concentrations of the biochemical variables measured in the selected population of the second phase of the baseline survey are shown in Table 3 . There were five $(1.5 \%)$ children with concentrations of retinol and RBP below $0.35 \mu \mathrm{mol} / 1$, indicative of vitamin A deficiency (World Health Organization, 1982). The percentage of children with $\mathrm{Hb}$ levels below $7.45 \mathrm{mmol} / \mathrm{l}$, indicative of anaemia, was 65.4 while PCV was less than 0.35 in 21.2 , ferritin was less than $10 \mu \mathrm{g} / \mathrm{l}$ in 1.2 , serum Fe was less than $10.74 \mu \mathrm{mol} / 1$ in 28.8 and $\mathrm{RBC}$ count was less than 4.12 million $/ \mathrm{mm}^{3}$ in 44.8 of the children. Using the multiple criteria of $\mathrm{Hb}, \mathrm{PCV}$ and serum $\mathrm{Fe}$ values as suggested by International Nutritional Anemia Consultative Group (1985), $48.4 \%$ of the children were below the cut-off points for the three variables. The $\mathrm{MCV}$ and $\mathrm{MCH}$ median values were within the upper range while 24.4 and $11.3 \%$ of the children had values of MCV and $\mathrm{MCH}$ respectively which were above the normal cut-off points. IgA, IgG and IgM were higher than the upper limit of the normal range in $8 \cdot 1,87.7$ and $88.3 \%$ of children respectively. Values for TT4/TBG quotient, TT3, TT4 and TSH were above normal limits in $6 \cdot 0,28.2,3.6$ and $5.4 \%$ of the children respectively, suggestive of hyperthyroidism (Boehringer Mannheim, Germany and Amersham International, UK). Hypothyroidism was observed in $8.6,1.8$ and $14.4 \%$ of the children based on the TT4/TBG quotient, TT4 and TSH levels respectively. 


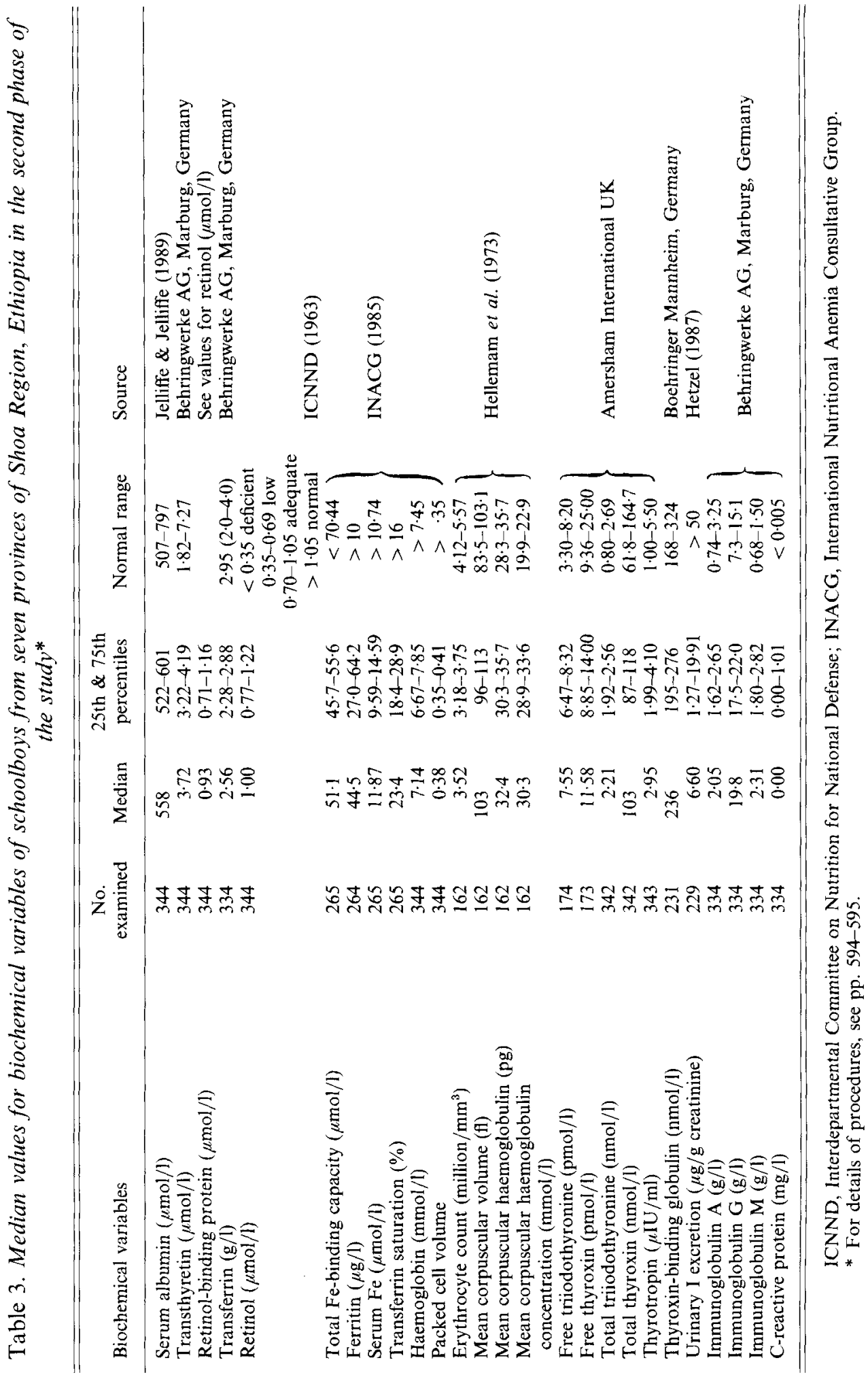


The median concentrations of protein, vitamin A and Fe variables by study sites grouped by altitude and major staple foods consumed are compared in Table 4 . Serum albumin, transferrin, TIBC, ferritin, PCV and CRP were significantly higher and RBP, retinol, serum $\mathrm{Fe}$, transferrin saturation, $\mathrm{Hb}$ and $\mathrm{IgM}$ were significantly lower in the lowland cereal staple areas (Kobo and Robi) than in the lowland ensete (Ensete ventricosum)-consuming areas (Chebona-Gurage). TTR, RBP, retinol, Hb, PCV, IgA, IgM and CRP were significantly higher in the highland ensete-staple areas (Kembatana-Hadya) than in the lowland cerealstaple areas, while serum albumin, TTR, RBP, transferrin, Hb, PCV, IgA and CRP were also significantly higher in the highland than the lowland ensete-staple areas.

Stool examination on 344 children showed that $22.0 \%$ did not have parasites while $31.6 \%$ had hookworm, $13.1 \%$ ascaris, $7.8 \%$ amoeba cyst, $4.9 \%$ strongyloides, $0.9 \%$ schistosoma, $11.3 \%$ double parasites, and the rest $(8.4 \%)$ other parasites. Malaria was reported in the lowland areas where the prevalence of anaemia was high.

The biochemical variables expressed in terms of goitre grade are shown in Table 5. Compared with those with no goitre or grade IA goitre, children with grade IB and II goitres were significantly heavier and taller (values not shown), had lower serum retinol, RBP, Fe, transferrin saturation, T4, TBG and IgM values, and higher serum ferritin, TIBC, blood $\mathrm{Hb}$ and $\mathrm{PCV}$, and TSH values. For T4 the values for all grades of goitre were significantly different from one another. TSH concentrations were significantly $(P<0 \cdot 001)$ inversely correlated with T4/TBG quotient. However, no significant correlation was observed between triiodothyronine (T3) and T4/TBG quotient (values not shown).

The correlations obtained between the various biochemical variables were used to develop the models shown in Figs. 1 and 2. In Fig. $1 \mathrm{Hb}$ has been taken as the central variable. On the one hand, it was significantly correlated with putative determinants of $\mathrm{Hb}$ concentration, namely retinol and ferritin. The triad retinol, RBP and TTR were significantly correlated with one another, while TTR, a marker for short-term malnutrition, was correlated with albumin, a marker for long-term malnutrition. In addition, the triad was also negatively correlated with CRP, indicated in Fig. 1 by the relationship with retinol. Ferritin was correlated with transferrin saturation which in turn was correlated with serum $\mathrm{Fe}$. On the other hand, $\mathrm{Hb}$ was significantly positively associated with variables dependent on $\mathrm{Hb}$ concentrations, namely $\mathrm{PCV}, \mathrm{MCHC}, \mathrm{MCH}$ and $\mathrm{RBC}$ count. $\mathrm{Hb}$ was negatively correlated with FT3, FT4, TT4 and TBG, while it was positively correlated with TSH (values not shown). PCV was also positively correlated with albumin (values not shown). Within the population as a whole, weight-for-age and height-for-age, which are measures of wasting and stunting respectively, were closely and positively associated with albumin, TTR, RBP, Hb, PCV, transferrin and TIBC. However, when the ensete-eating areas (Kembatana-Hadya and Chebona-Gurage) and the teff (Eragrostis teff)-eating areas (Kobo and Robi) were taken separately, these relationships for weight-for-age and height-for-age no longer held in the cereal-staple areas (except for RBP with weight-for-age) while there were stronger correlations in the ensete-staple areas (values not shown).

In Fig. 2 correlations between thyroid hormones are considered. TT4 and FT4 as well as TT3 and FT3 were positively correlated. TSH was negatively correlated with TT4 and FT4 and positively correlated with FT3. T4 and T3 in both free and combined forms were all correlated with TBG, which in turn was negatively correlated with the triad of retinol, RBP and TTR. Albumin was also positively associated with FT3 (values not shown). In the population as a whole, weight-for-age and height-for-age were negatively and strongly associated with FT3 $(-0.28$ and -0.29 respectively), FT4 ( -0.28 and -0.29 respectively), TT4 ( -0.22 and -0.20 respectively) and TBG $(-0.44$ and -0.43 respectively). These relationships did not hold in the cereal-staple area and only with respect to TT4 and TBG in the ensete-staple area. Urinary I excretion was positively associated with TT4 $(0 \cdot 20)$ and 
VITAMIN A, I AND FE STATUS IN SCHOOLCHILDREN
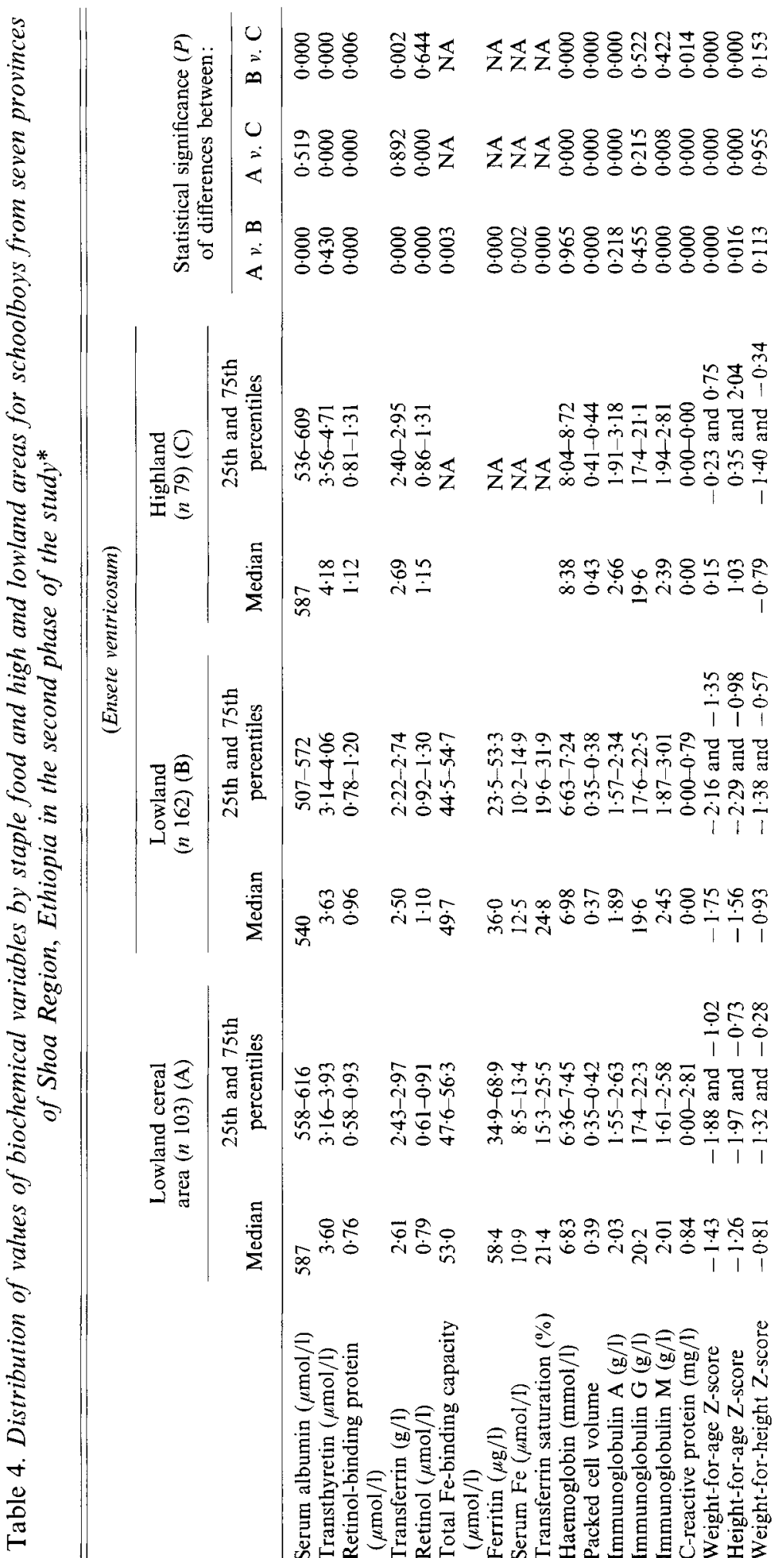

के

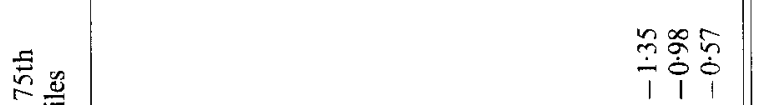

$\dot{\vec{a}}$

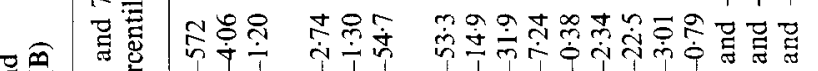

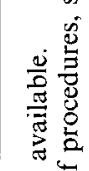

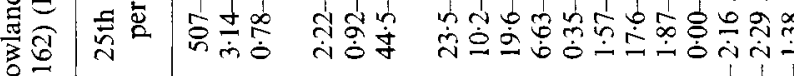

$\sum^{\frac{5}{g}}$

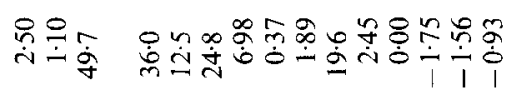

둥

$\stackrel{\frac{\pi}{2}}{\frac{\pi}{0}}$

芒数

近

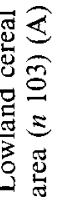

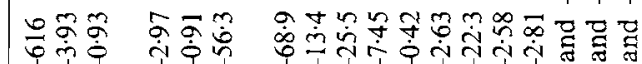

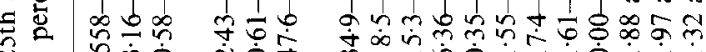
究

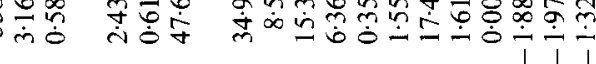

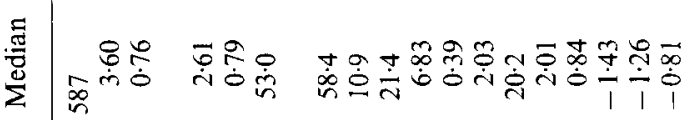

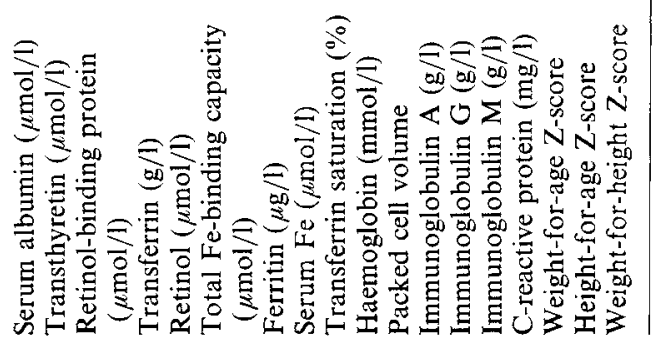




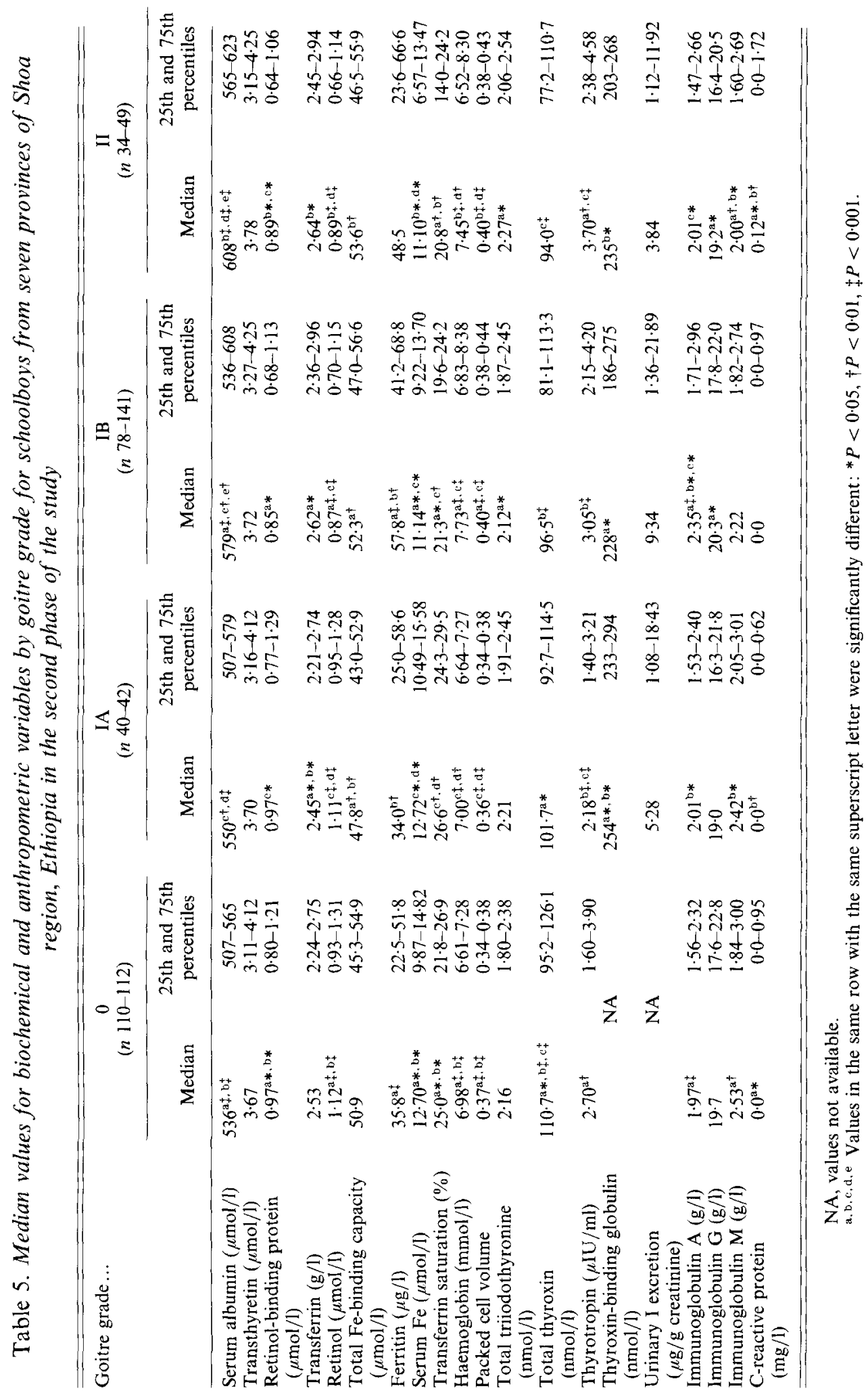




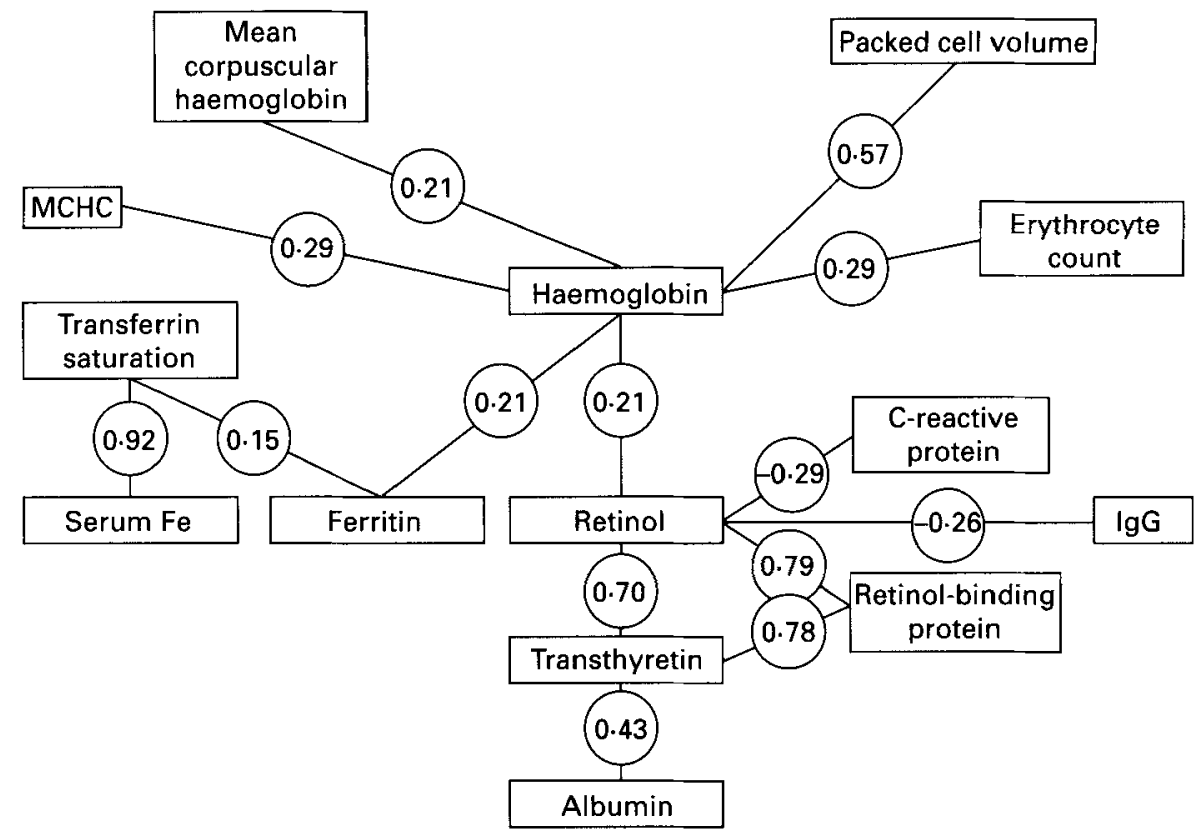

Fig. 1. Model based on correlations between variables for iron and vitamin A metabolism based on the study of Ethiopian schoolchildren from seven provinces of Shoa Region. IgG, immunoglobulin G; MCHC, mean corpuscular haemoglobin concentration. Values shown are correlation coefficients.

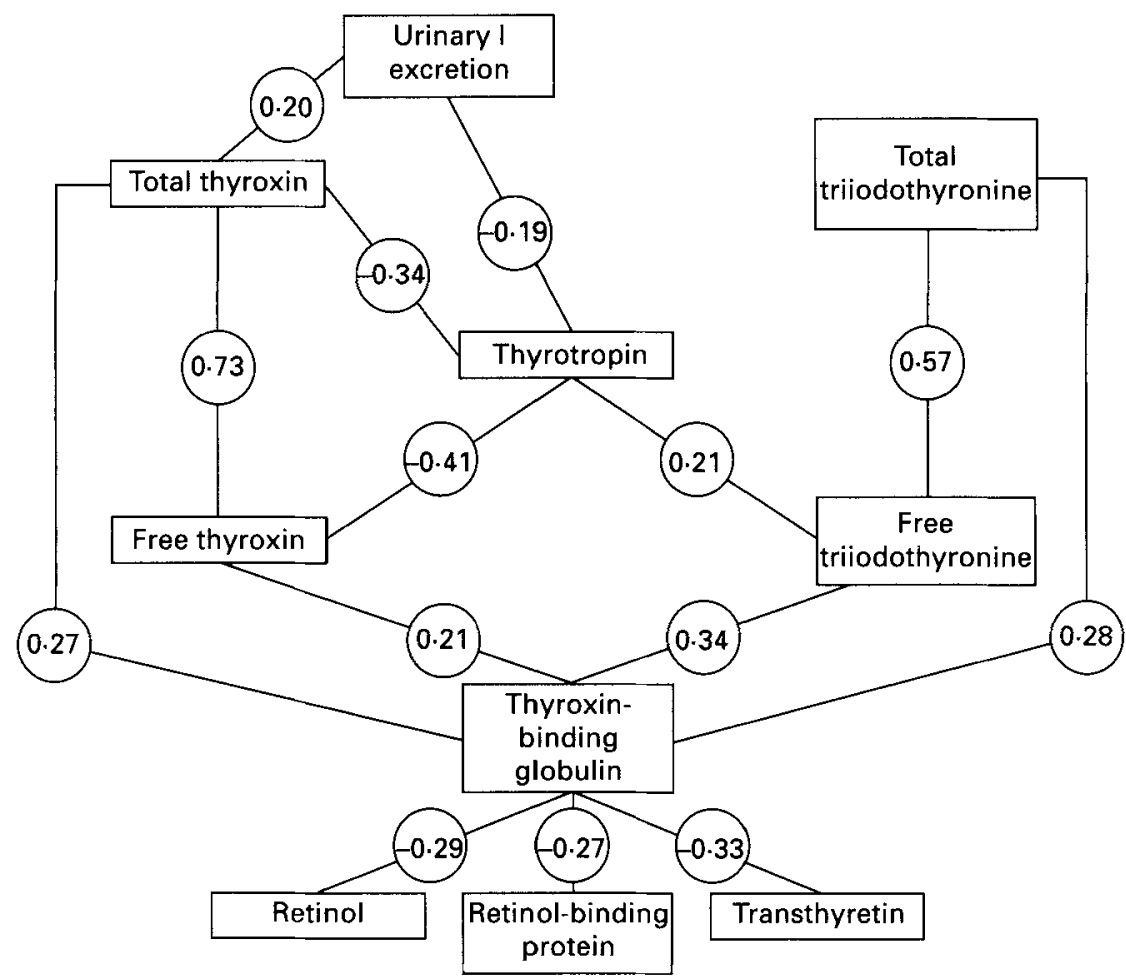

Fig. 2. Model based on correlations between variables for iodine and vitamin A metabolism based on the study of Ethiopian schoolchildren from seven provinces of Shoa Region. Values shown are correlation coefficients. 
Table 6. Iodine content of food items and drinking water from Ethiopian study areas

\begin{tabular}{|c|c|c|c|c|c|}
\hline & \multirow[b]{2}{*}{ Local name } & \multirow{2}{*}{$\begin{array}{l}\text { Collection } \\
\text { site }\end{array}$} & \multirow{2}{*}{$\begin{array}{l}\text { No. of } \\
\text { samples }\end{array}$} & \multicolumn{2}{|c|}{ I content (ng/g) } \\
\hline & & & & Mean & Range \\
\hline \multicolumn{6}{|l|}{ Type of food } \\
\hline \multicolumn{6}{|l|}{ Ensete (Ensete ventricosum) } \\
\hline Root & Amitcho & $\mathrm{M}, \mathrm{H} \dagger$ & 2 & $42 \cdot 7$ & $0.00-85 \cdot 4$ \\
\hline Pulp sap & Bulla & $\mathrm{M}, \mathrm{H}$ & 1 & 88.5 & 88.5 \\
\hline Pulp solid matter & Kocho & $\mathrm{M}, \mathrm{H}$ & 5 & $74 \cdot 3$ & $45 \cdot 8-85 \cdot 3$ \\
\hline $\begin{array}{l}\text { Kale (Brassica carinata), } \\
\text { boiled }\end{array}$ & Gommen & $\mathrm{M}, \mathrm{H}$ & 6 & 381.5 & $188 \cdot 0-598 \cdot 4$ \\
\hline \multicolumn{6}{|l|}{ Maize (Zea mays) } \\
\hline Roasted & Bequolo quolo & $\mathrm{M}, \mathrm{H}$ & 4 & $70 \cdot 6$ & $0 \cdot 0-163 \cdot 2$ \\
\hline Boiled & Bequolo nefro & $\mathrm{M}, \mathrm{H}$ & 2 & 132.5 & $54 \cdot 4-210 \cdot 5$ \\
\hline Bread & Bequolo kita & $\mathrm{M}, \mathrm{H}$ & 2 & $42 \cdot 5$ & $0.0-85.0$ \\
\hline $\begin{array}{l}\text { Sorghum (Sorghum vulgare), } \\
\text { whole grain }\end{array}$ & Mashila & $\mathrm{K}, \mathrm{R}^{*}$ & 2 & $26 \cdot 2$ & $23 \cdot 7-28 \cdot 6$ \\
\hline $\begin{array}{l}\text { Sweet potato (Ipomoea batatas), } \\
\text { fresh }\end{array}$ & Sequar dinich & $\mathrm{M}, \mathrm{H}$ & 1 & $145 \cdot 4$ & $145 \cdot 4$ \\
\hline $\begin{array}{l}\text { Teff (Eragrostis teff), } \\
\text { whole grain }\end{array}$ & Teff & $\mathrm{K}, \mathrm{R}$ & 2 & $163 \cdot 4$ & $145 \cdot 2-181 \cdot 5$ \\
\hline $\begin{array}{l}\text { Wheat (Triticum vulgare), } \\
\text { roasted }\end{array}$ & Sinde quolo & $\mathrm{M}, \mathrm{H}$ & 3 & $23 \cdot 7$ & $9 \cdot 2-39 \cdot 7$ \\
\hline Wheat-maize, roasted & Sinde quolo & $\mathrm{M}, \mathrm{H}$ & 1 & $79 \cdot 3$ & $79 \cdot 3$ \\
\hline \multicolumn{6}{|l|}{ Type of water source } \\
\hline Spring & & $\mathrm{H}$ & 2 & $3 \cdot 7$ & $2 \cdot 5-5 \cdot 0$ \\
\hline Spring & & $M$ & 3 & 7.7 & $2 \cdot 5-12 \cdot 5$ \\
\hline Spring & & $\mathrm{K}$ & 2 & $9 \cdot 2$ & $6 \cdot 0-12 \cdot 5$ \\
\hline Well & & $\mathrm{K}$ & 1 & $5 \cdot 0$ & $5 \cdot 0$ \\
\hline River & & $\mathrm{R}$ & 1 & $2 \cdot 0$ & $2 \cdot 0$ \\
\hline Pipe & & $\mathrm{R}$ & 1 & 1.7 & 1.7 \\
\hline Pipe & & $\mathrm{Z}^{*}$ & 1 & $6 \cdot 4$ & 6.4 \\
\hline
\end{tabular}

M, Mino; H, Hobicheka; K, Kobo; R, Robi; Z, Zuti.

* Yifatna-Timuga.

$\uparrow$ Kembatana-Hadya.

negatively associated with TSH $(-0 \cdot 19)$ in the total population and the cereal-staple area but not in the ensete-staple area.

The relative dose-response test conducted on eighty children showed that four children $(5.0 \%)$ had values above $14 \%$ (Flores et al. 1984; Solomons et al. 1990) while the median value was 0.00 ( 25 th and 75 th percentiles -8.25 and $5.20 \%$ respectively) indicating that the majority of the children had sufficient liver vitamin A stores.

\section{Food and water analysis}

The I content of the foods analysed varied from none in the maize and ensete samples to a mean of nearly $400 \mathrm{ng} / \mathrm{g}$ in the kale (Brassica carinata) samples while the I content in drinking water was low in all samples analysed (Table 6).

\section{Microbiological assay}

Fourteen samples of drinking water from the goitrous areas were analysed for bacterial contamination. All specimens showed growth of coliforms of differing intensity (Table 7). Of these specimens, six showed contamination with Escherichia coli and there was an 
Table 7. Bacteriological tests by study site and type of source of drinking water in Ethiopian study

\begin{tabular}{|c|c|c|c|c|c|c|}
\hline Site & $\begin{array}{l}\text { Type of } \\
\text { source } \dagger\end{array}$ & $n_{+}^{+}$ & $\begin{array}{l}\text { Coliform count } \\
\text { (per l) }\end{array}$ & $\begin{array}{l}\text { Escherichia coli } \\
\text { count (per 1) }\end{array}$ & $n \S$ & $\begin{array}{c}\text { Goitre } \\
\text { prevalence } \\
(\%)\end{array}$ \\
\hline \multicolumn{7}{|c|}{ Kembatana-Hadya } \\
\hline Hobicheka & Spring & 4 & $3.0 \times 10^{3}-3.4 \times 10^{4}$ & $5.0 \times 10^{3}$ & 3 & $80 \cdot 6$ \\
\hline Mino & Spring & 4 & $2.0 \times 10^{3}-7.9 \times 10^{4}$ & $2 \cdot 0 \times 10^{3}$ & 3 & $86 \cdot 8$ \\
\hline \multicolumn{7}{|c|}{ Yifatna-Timuga } \\
\hline Kobo & Spring & 2 & $1.4 \times 10^{4}-5.4 \times 10^{5}$ & $7.0 \times 10^{3}-1.4 \times 10^{4}$ & 2 & $79 \cdot 9$ \\
\hline Kobo & Well & 1 & $1.7 \times 10^{4}$ & 0 & & $79 \cdot 9$ \\
\hline Robi & River & 1 & $9.2 \times 10^{5}$ & $9.2 \times 10^{5}$ & & $37 \cdot 8$ \\
\hline Robi & Pipe & 1 & $1.2 \times 10^{4}$ & 0 & & 37.8 \\
\hline Zuti & Pipe & 1 & $0.8 \times 10^{3}$ & 0 & & $6 \cdot 5 * * *$ \\
\hline \multicolumn{7}{|c|}{ Tequlena-Bulga } \\
\hline Gudoberet & Spring & 1 & $1.7 \times 10^{4}$ & $1.7 \times 10^{4}$ & & $70 \cdot 0$ \\
\hline \multicolumn{7}{|c|}{ Chebona-Gurage } \\
\hline Emdibir & Pipe & 1 & $0.1 \times 10^{3}$ & 0 & & $13 \cdot 0$ \\
\hline Gubre & River & 1 & $8.4 \times 10^{4}$ & 0 & & $10 \cdot 5$ \\
\hline
\end{tabular}

$\dagger$ Source from which most of the study subjects obtained their drinking water.

$\ddagger$ No. of sources from which samples were collected.

$\S$ No. of specimens which showed presence of $E$. coli.

Values were significantly different from the goitre rates in Kobo and Robi: $* * * P<0.001$.

indication that the high prevalence of goitre was related to the presence of $E$. coli in drinking water as the prevalence rate of goitre in Zuti was significantly lower $(P<0.001)$ than in the other areas where the $E$. coli count was higher (Table 7).

\section{DISCUSSION}

The prevalence, sex and age distributions of gross goitre in the present study were not very different from those of schoolchildren at the national level (Wolde-Gebriel et al. 1993a). Thus, the prevalence rates of gross and visible goitre were 32.7 and $1.9 \%$ respectively in the present study, compared with 30.6 and $1.6 \%$ respectively at the national level.

The median TT3 and TSH values of our study children were higher and those of TT4 lower than the values reported for Ethiopian university and nursing students (Wassie \& Abdulkadir, 1990). In I-deficient areas TT3 thyrotoxicosis due to high TT3 was reported (Hollander et al. 1972; Abdulkadir \& Besrat, 1981) but in our study, where the goitre rate was high, deviation from the suggested reference value was not sufficient to classify the children as hyperthyroid.

In the present study the prevalence of Bitot's spots was $0.9 \%$. This indicates that the problem is of public health importance as the prevalence is above the $0.5 \%$ cut-off point set by the World Health Organization (1982). The higher prevalence in males than in females is also similar to the findings of the national survey. The vitamin A store in liver as evidenced from the relative dose-response was satisfactory except for four children. In these four children (two from the cereal-staple areas and two from the ensete-staple areas) the serum retinol values were less than $0.35 \mu \mathrm{mol} / 1$ confirming the biological validity of the relative dose-response test (Solomons et al. 1990).

In the first phase of the assessment all children with indications of paleness were registered for inclusion in the second phase. Hence, $18.6 \%$ of the children examined were 
diagnosed as clinically anaemic while in children selected from this group $65.4 \%$ had $\mathrm{Hb}$ values less than $7.45 \mathrm{mmol} / \mathrm{l}$, which is the cut-off point set by the World Health Organization (1972); 48.4\% were classed as anaemic based on multiple criteria and $21.2 \%$ had PCV values less than $0 \cdot 35$. Thus, assuming that all subjects with anaemia showed clinical signs, the overall prevalence of anaemia would be about $10 \%$.

Studies carried out by others have concluded that non-nutritional factors may be responsible for the anaemia seen in parts of the country (Interdepartmental Committee on Nutrition for National Defense, 1959; Hofvander, 1968; Gebre-Medhin et al. 1976). In the cereal-staple areas teff is consumed and, apart from the relatively high $\mathrm{Fe}$ content of the grain itself, the teff as consumed contains much Fe derived from contamination with soil during threshing (Mengesha, 1966; Besrat et al. 1980). In the ensete-staple areas kale would provide substantial $\mathrm{Fe}$ in the diet.

The close correlations observed between the various biochemical and anthropometric variables in the population as a whole are sometimes artificial. Thus, in the correlations presented in Figs. 1 and 2 only those significant for the population as a whole and for the cereal- and ensete-staple areas separately have been reported and used for the basis of developing hypotheses. The artifact arises from the differences between the areas.

It is interesting to note that in Fig. 1 the strength of the relationship between serum retinol and blood $\mathrm{Hb}$ is as strong as the relationship between serum ferritin and blood $\mathrm{Hb}$ and stronger than the relationship between serum ferritin and transferrin saturation since ferritin levels provide an indication of Fe stores. A similar relationship between serum retinol and blood $\mathrm{Hb}$ was found by several authors (Mejía et al. 1977; Mohanram et al. 1977; Hodges et al. 1978; Mejía \& Arroyave, 1982; Bloem et al. 1990). More recently, such a relationship was also observed in a cross-sectional study on the Fe status of pregnant women in West Java, Indonesia (Suharno et al. 1992). Studies in Asia have also shown a relationship between serum vitamin A concentration and PCV (Bloem et al. 1989; Suharno et al. 1992) but this was not seen in the present study even though $\mathrm{Hb}$ concentration was correlated with $\mathrm{PCV}, \mathrm{RBC}$ count, $\mathrm{MCHC}$ and $\mathrm{MCH}$. This may be because some of the anaemia is macrocytic, indicating malaria-induced deficiency of folic acid and/or vitamin $B_{12}$. There are several possible sites where vitamin A may exert its action: absorption of $\mathrm{Fe}$ from the gut, transport in serum, uptake and release of Fe in the liver, uptake of Fe by the bone marrow (which is the site of $\mathrm{Hb}$ synthesis) and in $\mathrm{Hb}$ synthesis itself. Absorption of Fe seems to be, in fact, increased in vitamin A deficiency (Sijtsma et al. 1993). As far as Fe transport is concerned, we found no relationship between vitamin A and transferrin concentrations in the present study or in our study of pregnant women in Indonesia (Suharno et al. 1992), but we did in the study of children in an area of severe vitamin A deficiency in the Hararge Region of Ethiopia (Wolde-Gebriel et al. 1993b), while others have found a negative correlation (Bloem et al. 1989). Uptake of Fe by the liver does not seem to be affected as it is known that vitamin A deficiency results in hepatic $\mathrm{Fe}$ accumulation (Staab et al. 1984; Sijtsma et al. 1993), although it may well be that release of Fe from the liver is affected. Uptake of Fe by the haematopoietic tissues could possibly be inhibited by vitamin A deficiency since we have found that Fe accumulation in the femur is lowered in vitamin A-deficient rats (Sijtsma et al. 1993), but it may well be that haematopoiesis itself is directly affected as Douer \& Koeffler (1982) have shown that retinoic acid enhances the growth of human erythroid progenitor cells.

The association between retinol, RBP and TTR has been found in our earlier study in Hararge (Wolde-Gebriel et al. 1993 b) and in Nigeria (James et al. 1984), and is explained by the formation of a one-for-one complex of retinol with RBP and, at low TTR levels, of the three molecules (Raz et al. 1969). It is only at levels of TTR above $0.7-1.0 \mu \mathrm{mol} / 1$ that its concentration is no longer linearly related to that of the other two. 
In Fig. 2 several relationships highlight the mechanisms by which the body compensates for low I intake. As would be expected, TT4 is positively correlated with urinary I excretion. The relationships of TSH with urinary I excretion, TT4 and FT4 (all negative), and with FT3 (positive) are in line with the compensatory mechanism by which TSH stimulates thyroxin $5^{\prime}$-deiodinase $(E C 3.8 .1 .4)$ activity resulting in the conversion of less active T4 to more active T3 (Erickson et al. 1982) when the availability of I for the synthesis of thyroid hormone is limited. This mechanism was reported to be responsible for the absence of sub-clinical hypothyroidism observed in goitrous areas in India and New Guinea (Kochupillai et al. 1973; Pharoah et al. 1973).

The negative association between TBG and the triad of retinol, RBG and TTR shown in Fig. 2 would explain the shift in binding of T4 from TTR to TBG when rats are made vitamin A-deficient (Oba \& Kimura, 1980). However, since $90 \%$ of thyroid hormones are normally carried on TBG, it would not lend support to the hypothesis that vitamin A plays a role in the development of goitre. Such an hypothesis has been developed on the basis of interrelationships observed between vitamin A nutriture and occurrence of goitre on the Island of Krk in Yugoslavia (Horvat \& Maver, 1958) and in Senegal (Ingenbleek \& De Visscher, 1979). The low urinary I excretion also indicates that the goitre problem in the surveyed areas is due primarily to I deficiency rather than to other factors although, as mentioned previously, bacterial contamination of water may also play a significant role.

This and earlier studies clearly indicate that I deficiency disorders, as manifested by goitre, and vitamin A deficiency are the two major nutritional deficiency problems of public health significance in Ethiopia. Unlike in many developing countries, nutritional anaemia is not a problem of major concern to the country. The present paper also shows that the effects of the deficiencies of the various nutrients cannot be considered in isolation because they are very much interrelated.

Financial assistance was provided by the Joint UNICEF/WHO Nutrition Support Programme and the Office of Nutrition of the United States Agency for International Development for which the authors are very grateful. They thank Getachew Zenebe and other staff members of the Ethiopian Nutrition Institute who assisted with the work.

\section{REFERENCES}

Abdulkadir, J. \& Besrat, A. (1981). Thyrotoxicosis due to isolated elevation of triiodothyronine in Ethiopian patients. East African Medical Journal 58, 785-789.

Anonymous (1990). Vitamin A and malnutrition/infection complex in developing countries. Lancet 336, 1349-1351.

Besrat, A., Admasu, A. \& Ogbai, M. (1980). Critical study of the iron content of tef (Eragrostis tef). Ethiopian Medical Journal 18, 45-52.

Bloem, M. W., Wedel, M., Egger, R. J., Speek, A. J., Schrijver, J, Saowakontha, S. \& Schreurs, W. H. P. (1989). Iron metabolism and vitamin A deficiency in children in Northeast Thailand. American Journal of Clinical Nutrition 50, 332-338.

Bloem, M. W., Wedel, M., van Agtmaal, E. J., Speek, A. J., Saowakontha, S. \& Schreurs, W. H. P. (1990). Vitamin A intervention: short-term effects of a single, oral, massive dose on iron metabolism. American Journal of Clinical Nutrition 51, 76-79.

Delange, F., Bastani, S., Benmiloud, M., DeMaeyer, E., Isayama, M. G., Koutras, D., Muzzo, S., Niepomniszcze, H., Pandav, C. S. \& Riccabona, G. (1986). Definition of endemic goitre and cretinism, classification of goitre size and severity of endemias, and survey technique. In Towards the Eradication of Endemic Goitre, Cretinism, and Iodine Deficiency. Scientific Publication no. 502, pp. 373-376 [J. T. Dunn, E. A. Pretell, C. H. Daza and F. E. Viteri, editors]. Washington, DC: PAHO/WHO.

DeMaeyer, E. \& Adiels-Tegman, M. (1985). The prevalence of anaemia in the world. World Health Statistics Quarterly 38, 302-316.

Douer, D. \& Koeffler, H. P. (1982). Retinoic acid enhances growth of human early erythroid progenitor cells in vitro. Journal of Clinical Investigation 69, 1039-1041. 
Doumas, B. T., Watson, W. \& Biggs, H. G. (1971). Albumin standards and the measurement of serum albumin with bromocresol green. Clinica Chimica Acta 31, 87-96.

Erickson, V. J., Cavalieri, R. R. \& Rosenberg, L. L. (1982). Thyroxine 5 '-deiodinase of rat thyroid, but not that of liver is dependent on TSH. Endocrinology 111, 434440.

Fink, P. C., Römer, M., Haekel, R., Fateh-Moghadam, A., Delanghe, J., Gressner, A. M. \& Dubs, R. (1989). Measurement of protein with the Behring nephelometer: a multicentre evaluation. Journal of Clinical Chemistry and Clinical Biochemistry 27, 261-276.

Flores, H., Campos, F., Arauja, C. R. C. \& Underwood, B. (1984). Assessment of marginal vitamin A deficiency in Brazilian children using the relative dose response procedure. American Journal of Clinical Nutrition $\mathbf{4 0}$, 1281-1289.

Gebre-Medhin, M., Killander, A., Vahlquist, B. \& Wuhib, E. (1976). Rarity of anaemia of pregnancy in Ethiopia. Scandinavian Journal of Haematology 16, 168-175.

Grant, J. P. (1991). The State of the World's Children 1991. New York: Oxford University Press on behalf of UNICEF.

Hellemam, P. W., Sixma, J. J., van der Plas, P. M. \& Dudoc de Wit, C. (1973). Hematologie. Amsterdam: Elsevier.

Hetzel, B. S. (1987). An overview of the prevention and control of iodine deficiency disorders. In The Prevention and Control of Iodine Deficiency Disorders, pp. 7-31 [B. S. Hetzel, J. T. Dunn and J. B. Stanbury, editors]. Amsterdam: Elsevier.

Hodges, R. E., Sauberlich, H. E., Canham, J. E., Wallace, D. L., Rucker, R. B., Mejia, L. A. \& Mohanram, M. (1978). Hematopoietic studies in vitamin A deficiency. American Journal of Clinical Nutrition 31, 876-885.

Hofvander, Y. (1968). Hematological investigations in Ethiopia, with special reference to a high iron intake. Acta Medica Scandinavica Suppl. 494, 1-74.

Hollander, C. S., Mitsuma, T., Shenkman, L., Stevenson, C., Pineda, G. \& Silva, E. (1972). T3 toxicosis in an iodine deficient area. Lancet ii, 1276-1278.

Horvat, A. \& Maver, H. (1958). The role of vitamin A in the occurrence of goitre on the island of Krk, Yugoslavia. Journal of Nutrition 68, 189-203.

Ingenbleek, Y. \& De Visscher, M. (1979). Hormonal and nutritional status: critical conditions for endemic goiter epidemiology? Metabolism 28, 9-19.

Interdepartmental Committee on Nutrition for National Defense (1959). Ethiopia - Nutrition Survey. Washington, DC: US Government Printing Office.

Interdepartmental Committee on Nutrition for National Defense (1963). Manual for Nutrition Surveys, 2 nd ed. Bethesda, MD: National Institute of Health.

International Nutritional Anemia Consultative Group (1977). Guidelines for the Eradication of Iron Deficiency Anemia. Washington, DC: INACG.

International Nutritional Anemia Consultative Group (1985). Measurements of Iron Status. Washington, DC: INACG.

James, H. O., West, C. E., Duggan, M. B. \& Ngwa, M. (1984). A controlled study on the effect of injected watermiscible retinyl palmitate on plasma concentrations of retinol and retinol-binding protein in children with measles in Northern Nigeria. Acta Paediatrica Scandinavica 73, 22-28.

Jelliffe, D. B. \& Jelliffe, E. F. (1989). Community Nutritional Assessment: With Special Reference to Less Technically Developed Countries, pp. 39. New York: Oxford University Press.

Kochupillai, N., Karmarkar, M. G., Weightman, D., Hall, R., Deo, M. G., Mekendrick, M., Everd, D. C. \& Ramalingaswami, V. (1973). Pituitary-thyroid axis in Himalayan endemic goitre. Lancet ii, 1021-1024.

Mejía, L. A. \& Arroyave, G. (1982). The effect of vitamin A fortification of sugar on iron metabolism in preschool children in Guatemala. American Journal of Clinical Nutrition 36, 87-93.

Mejía, L. A., Hodges, R. E., Arroyave, G., Viteri, F. \& Torun, B. (1977). Vitamin A deficiency and anemia in Central American children. American Journal of Clinical Nutrition 30, 1175-1184.

Mengesha, M. H. (1966). Chemical composition of tef (Eragrostis tef) compared with that of wheat, barley and grain sorghum. Economic Botany 20, 268-273.

Mohanram, M., Kulkarni, K. A. \& Reddy, V. (1977). Hematological studies in vitamin A-deficient children. International Journal of Vitamin and Nutrition Research 47, 389-393.

Oba, K. \& Kimura, S. (1980). Effect of vitamin A deficiency on thyroid function and serum thyroid levels in the rat. Journal of Nutritional Science and Vitaminology 26, 327-334.

Pharoah, P. O. D., Lawton, N. F., Ellis, S. M., Williams, E. S. \& Ekins, R. P. (1973). The role of triiodothyronine (T3) in the maintenance of euthyroidism in endemic goitre. Clinical Endocrinology 2, 193-199.

Raz, A., Shiratory, T. \& Goodman, D. S. (1969). The interaction of thyroxine with human plasma prealbumin and with the pre-albumin-retinol binding protein complex. Journal of Biological Chemistry 244, 3230-3237.

Sandell, E. B. \& Kolthof, I. M. (1937). Micro determination of jodine by a catalytic method. Mikrochemica Acta 1, 9-25.

Schade, A. L., Oyama, J., Reinhardt, R. W. \& Miller, J. R. (1954). Bound iron and unsaturated iron-binding capacity of serum: rapid and reliable quantitative determination. Proceedings of the Society for Experimental Biology and Medicine 87, 443-448.

Sijtsma, K. W., van den Berg, G. J., Lemmens, A. G., West, C. E. \& Beynen, A. C. (1993). Iron status in rats fed diets containing marginal amounts of vitamin A. British Journal of Nutrition (In the Press). 
Solomons, N.W., Morrow, F.D., Vasquez, A., Bulux, J., Guerrero, A. \& Russell, R. M. (1990). Test-retest reproducibility of the relative dose response for vitamin $A$ status in Guatemalan adults: issue of diagnostic sensitivity. Joumal of Nutrition 120, 738-744.

Staab, D. B., Hodges, R. E., Metcalf, W. K. \& Smith, J. L. (1984). Relationship between vitamin A and iron in the liver. Journal of Nutrition 114, 840-844.

Suharno, D., West, C. E., Muhilal, Logman, M. H. G. M., de Waart, F. G., Karyadi, D. \& Hautvast, J. G. A. J. (1992). Cross sectional study on the iron and vitamin A status of pregnant women in West Java, Indonesia. American Journal of Clinical Nutrition 56, 988-993.

van Kampen, E. J. \& Zijlstra, W. G. (1961). Standardization of hemoglobinometry. 11. The hemiglobincyanide method. Clinica Chimica Acta 6, 538-544.

Wassie, E. \& Abdulkadir, J. (1990). Normal thyroid function values in Ethiopians. Ethiopian Medical Journal 28, 139-143.

Wolde-Gebriel, Z., Demeke, T. \& West, C. E. (1991). Xerophthalmia in Ethiopia: a nationwide ophthalmological, biochemical and anthropometric survey. European Journal of Clinical Nutrition 45, 469-478.

Wolde-Gebriel, Z., Demeke, T., West, C. E. \& van der Haar, F. (1993a). Goitre in Ethiopia. British Journal of Nutrition 69, 257-268

Wolde-Gebriel, Z., Gebru, H., Fisseha, T.\& West, C. E. (1993b). Vitamin A, iron and iodine status in children with severe vitamin A deficiency in a rural village in the Hararge Region of Ethiopia. European Journal of Clinical Nutrition 47, 104-114.

World Health Organization (1972). Nutritional Anaemias. Technical Report Series no. 503. Geneva: WHO.

World Health Organization (1982). Control of Vitamin A Deficiency and Xerophthalmia. Technical Report Series no. 672. Geneva: WHO. 